\title{
Febre amarela: estudo de um surto
}

\author{
Yellow fever: study of an outbreak
}

\author{
Mirtes Ribeiro $^{1,2}$ e Carlos Maurício de Figueiredo Antunes ${ }^{2,3,4,5}$
}

\begin{abstract}
RESUMO
O estudo objetivou descrever um surto de febre amarela ocorrido nos municípios sob jurisdição da Gerência Regional de Saúde de Diamantina/MG, entre 2002/2003, classificando 36 casos de FA. Tratou-se de surto autóctone de febre amarela silvestre. Identificou-se falha na cobertura vacinal e baixa detecção de casos leves. Entre os casos, 33 (91,7\%) eram homens. A idade variou entre 16 a 67 anos. Classificaram-se como graves 19 (52,8\%) casos. A letalidade acometeu 12 (33,3\%) indivíduos homens. Os infectados procediam de área rural e manifestaram febre, cefaléia, vômito, icterícia, mialgia, oligúria e sinais hemorrágicos. A vigilância laboratorial foi o fator determinante para o diagnóstico do surto. Ao descrever os achados epidemiológicos e clínicos, este estudo subsidia o diagnóstico e a classificação da doença. Deduz-se uma relação do surto com desmatamentos e um potencial de risco regional para febre amarela devido o desenvolvimento turístico local.
\end{abstract}

Palavras-chaves: Febre amarela. Surto. Vigilância epidemiológica. Diagnóstico laboratorial e clínico.

\section{ABSTRACT}

This study had the aim of describing an outbreak of yellow fever that occurred in the municipalities under the jurisdiction of the Regional Healthcare Administration of Diamantina, Minas Gerais, between 2002 and 2003, in which 36 cases were notified. This was an autochthonous outbreak of wildtype yellow fever. Failure of vaccinal coverage and low levels of detection of mild cases were found. Among the cases, $33(91.7 \%)$ were male and the age range was from 16 to 67 years. Nineteen (52.8\%) of the cases were classified as severe and 12 men (33.3\%) died of the disease. All of the cases came from rural areas and presented fever, headache, vomiting, jaundice, myalgia, oliguria and signs of hemorrhage. Surveillance through laboratory tests was the determining factor in diagnosing the outbreak. By describing the epidemiological and clinic findings, this study contributes towards diagnosing and classifying this disease. It was deduced that there is a relationship between deforestation, and outbreaks, and that there is a potential regional risk of yellow fever because of the local development of tourism.

Key-words: Yellow fever. Outbreak. Epidemiological surveillance. Clinical and laboratory diagnosis.

A febre amarela (FA) é uma doença febril aguda, endêmica nas regiões tropicais das Américas e África. A forma silvestre é transmitida, principalmente, entre macacos e por mosquitos dos gêneros Haemogogus e Sabethes nas Américas; o homem se infecta quando penetra nesse ecossistema. A forma urbana tem como vetor principal o Aedes aegypti e é mantida por meio da transmissão homem-mosquito-homem ${ }^{20}$.

A Organização Mundial de Saúde (OMS) classifica um terceiro ciclo de transmissão que, até os dias atuais, somente foi identificado na África, denominado de intermediário. Ocorre nas regiões de savanas e semi-áridos acometendo vilarejos isolados que têm como vetor os mosquitos semidomésticos que infectam primatas e homens ${ }^{24}$.

1. Departamento de Enfermagem, Universidade Federal dos Vales do Jequitinhonha e Mucuri, Diamantina, MG. 2. Programa de Mestrado em Ciências da Saúde: Infectologia e Medicina Tropical da Universidade Federal de Minas Gerais, Belo Horizonte, MG. 3. Department of Epidemiology, The Johns Hopkins University Blomberg School of Public Health, MA, USA. 4. Núcleo de Pós Graduação e Pesquisa, Santa Casa de Misericórdia de Belo Horizonte, Belo Horizonte, MG. 5. Departamento de Ciências Básicas, Universidade Federal de Minas Gerais, Belo Horizonte, MG.

Endereço para correspondência: Ms. Mirtes Ribeiro. Rua da Glória 187, Centro. 39100-000 Diamantina, MG.

Tel: 5538 8811-9170

e-mail: mirtesr@ufmg.edu.br, mirtes@ufvim.edu.br,

Recebido para publicação em 01/12/2008

Aceito em 29/09/2009
A febre amarela é uma das doenças de notificação compulsória que está presente no International Health Regulations, sendo seu registro oficial iniciado em 1950. Mesmo com a subnotificação mascarando a real magnitude da situação, é possível identificar que no período de 1950-2004 a doença apresentou tendência crescente $^{25}$.

Nas Américas, os casos são esporádicos e os surtos com taxas de ataque de 1-2/1.000 pessoas ${ }^{16}$. Os investimentos em infraestrutura urbana desenvolvidos nas primeiras décadas do século $\mathrm{XX}$ e as medidas de combate ao vetor, realizadas em função das epidemias de FA urbana, reduziram drasticamente a ocorrência de casos, chegando a alcançar no Brasil a erradicação da forma urbana em 1942. Em 1954, foi registrado o último foco de FA urbana nas Américas, em Trinidad-Tobago.

Manteve-se, exclusivamente, silvestre nos países endêmicos da América do Sul, até 2008, quando foi identificada a transmissão por ciclo urbano no Paraguai ${ }^{7}$. A forma silvestre não pode ser erradicada e tem sido objeto de intervenções visando ao seu controle. A manutenção de coberturas vacinais altas e homogêneas é uma medida indispensável.

A delimitação das áreas de risco para ocorrência de FA silvestre está cada dia mais difícil, como está também mais difícil identificar se os casos registrados são transmitidos por vetores 
silvestres ou urbanos em virtude da superposição de áreas infestadas por duas espécies de mosquitos ${ }^{13}$.

Em 2003, o Ministério da Saúde constatou a necessidade de ampliação da área de risco de FA silvestre, uma vez que houve transmissão em 2000 nas regiões da Bahia e de São Paulo, e, em 2001 e 2002, de Minas Gerais (MG). Infestadas por Aedes $A$ egypti, estas regiões não apresentavam casos autóctones da forma silvestre há muitos anos. Ocorreu ainda em 2001, no Oeste do Rio Grande do Sul, circulação do vírus com óbitos de macacos confirmados laboratorialmente. Nesta região também não havia registro de epizootias por FA há muitos anos. Observa-se nas Figuras 1 e 2, a expansão das áreas de risco nos mapas do Brasil pelas definições de 1998 e a redefinição em 2003.

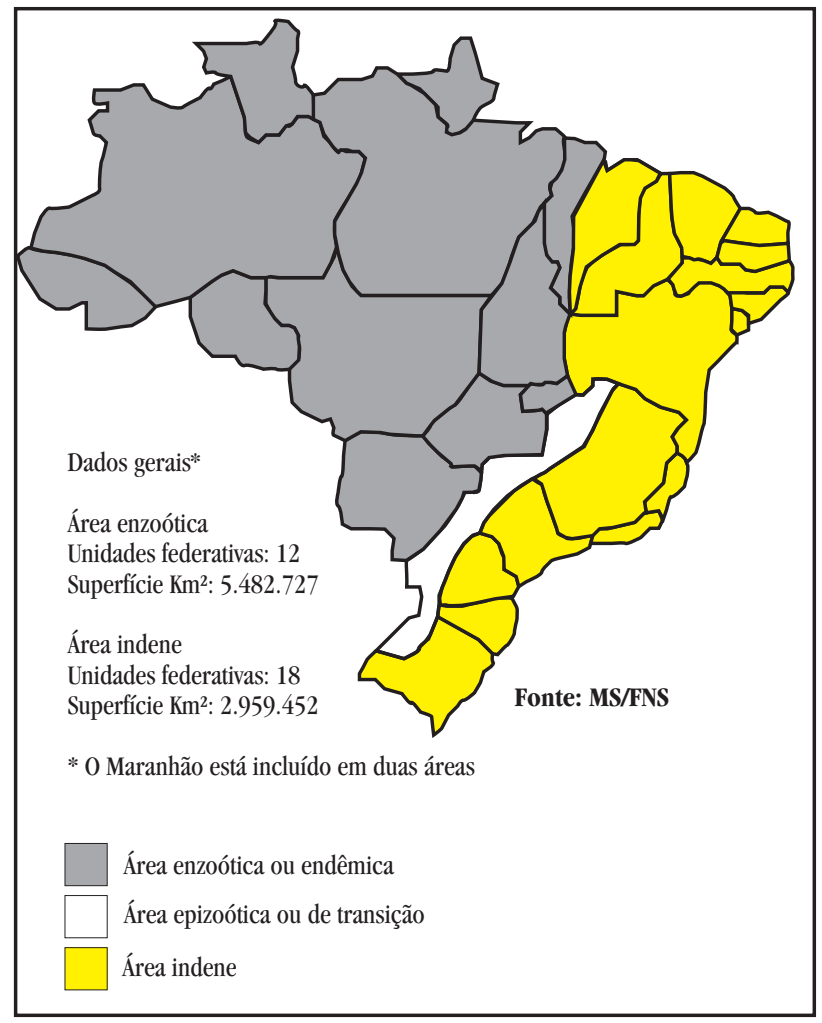

FIGURA 1

Áreas epidemiológicas de febre amarela silvestre, Brasil, 1998

Em 2004, foram confirmados cinco casos humanos isolados, restritos à região amazônica. Em 2005, foram registrados três casos de FA, todos procedentes da região amazônica, sendo que todos evoluíram para o óbito. Em 2006, foram confirmados dois casos da doença nos estados do Amazônias e Mato Grosso, ambos com evolução para óbito. Em 2007, foram registrados 06 casos distribuídos em quatro estados (Amazonas, Pará, Roraima e Goiás). Em 2008, até o dia 14 de março, foram confirmados 38 casos com 13 óbitos e 4 casos permaneciam ainda em investigação, tendo as áreas silvestres do Goiás, Mato Grosso do Sul, Distrito Federal, Mato Grosso e Paraná como prováveis locais de infecçãa $0^{71011}$.

Este estudo objetivou descrever as características epidemiológicas e clínicas de um surto de FA ocorrido em MG, Brasil.

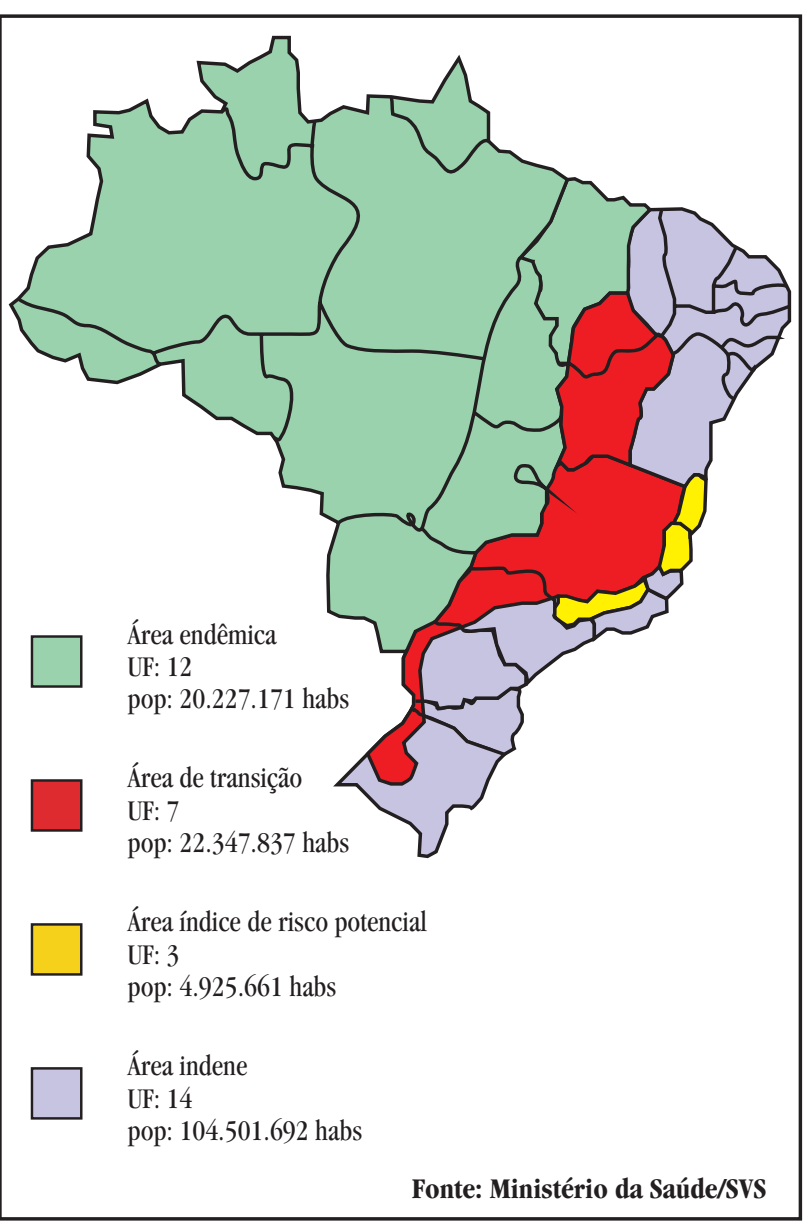

FIGURA 2

Áreas epidemiológicas de febre amarela silvestre, Brasil, 2003.

\section{PACIENTE E MÉTODOS}

Critério de seleção. Dos 63 casos confirmados de FA do surto de 2002/2003 em MG, selecionou-se aqueles dos municípios sob jurisdição da Gerência Regional de Saúde de Diamantina (GRSD), um total de 36 indivíduos, procedentes dos municípios de Serro, Sabinopólis e Alvorada de Minas. Esses municípios compõem a rota turística da Estrada Real e a divisão política e geográfica utilizada pelos órgãos de saúde.

Procedimentos. Foram fontes de coleta de dados os doentes ou suspeitos de FA, por meio de entrevista, exames clínicos e laboratoriais; seus familiares, amigos e vizinhos por busca ativa e os prontuários dos serviços de saúde. Além disso, fez-se busca nos Sistemas de Informação do Programa Nacional de Imunização (SI-PNI), no Programa de Controle de Febre Amarela e Dengue (PCFAD) e no Instituto Estadual de Florestas (IEF). As informações foram coletadas por funcionários do serviço de vigilância epidemiológica. Utilizou-se como instrumentos para coleta de dados, anotações em diário de campo e ficha de investigação para FA do Sistema de Informação de Agravos de Notificação (SINAN). Realizouse busca ativa casa-a-casa em toda a zona rural dos municípios acometidos, para fins de aplicar vacina e para inquérito sobre FA.

Avaliação epidemiológica e clínica. Os casos suspeitos identificados na busca ativa ou por demanda espontânea, foram 
notificados. Adequaram-se os critérios de definição de caso suspeito, como sendo todo indivíduo que teve contato com mata (zona rural) nos últimos 15 dias com quadro clínico sugestivo (febre aguda prá menos de 10 dias, associado a outros sintomas importantes como cefaléia, mialgia, dor abdominal, prostração), sem comprovação de vacina ou indivíduo que apresentasse icterícia ou manifestações hemorrágicas, independente do estado vacinal e de outros sintomas. Foi considerado vacinado somente quem apresentou comprovação por escrito (cartão de vacina, cartão espelho, prontuário, ficha de atendimento e livro de registro). Todo caso notificado como suspeito foi investigado e encaminhado para tratamento de suporte diante de sintomas ou vacinação perante ausência de história clínica e vacinal.

Avaliação laboratorial. Apesar do diagnóstico virológico ser o teste confirmatório, o diagnóstico sorológico foi o mais empregado, sendo utilizada a técnica de Reação imunoenzimática de captura de IgM (Mac-ELISA) como primeira opção, por ser a mais indicada para diagnóstico de infecção recente. Dos casos notificados, foi coletado sangue para sorologia e, em alguns casos esporádicos, foram coletadas amostras para isolamento viral. A coleta de sangue para sorologia foi realizada nos laboratórios da região ou no domicílio do paciente, em frasco estéril e conservado em isopor com gelo. A centrifugação foi realizada imediatamente após coleta e o soro encaminhado ao laboratório de referência estadual, Fundação Ezequiel Dias (FUNED). Nas amostras detectadas com resultado indeterminado ou insuficiente, coletou-se nova amostra ou o exame foi repetido. As amostras sanguíneas para isolamento viral foram coletadas até 3 dias após início de sintomas e conservadas em temperatura inferior a menos $20^{\circ} \mathrm{C}$ em nitrogênio. Os exames laboratoriais inespecíficos foram realizados pelos laboratórios locais. Nos casos considerados suspeitos, somente após o óbito, realizou-se isolamento viral de amostra de tecido de fígado.

Definição de caso confirmado. Definiu-se por critério clínico epidemiológico todo suspeito de febre amarela que evoluiu para óbito em menos de 10 dias, sem confirmação laboratorial, no início ou curso do surto. E, por critério laboratorial, inclusive o assintomático, quem apresentou pelo menos uma das seguintes condições: isolamento de vírus, teste de Mac-ELISA (IgM) positivo em indivíduos não vacinados ou com aumento de 4 vezes ou mais nos títulos de anticorpos do tipo IgG, pela técnica de inibição de hemaglutinação (IH) ou IgG-ELISA, achados histopatológicos compatíveis ou detecção de genoma viral.

Variáveis do estudo. Foram agrupadas em cinco categorias e classificadas em dados pessoais (código de identificação, endereço, município, sexo e idade); dados clínicos (vacinação, febre, icterícia, cefaléia, vômito, hematêmese, hematúria, melena, oligúria e mialgia); exames laboratoriais inespecíficos, (aspartato aminotransferase (AST) e alanina aminotransferase (ALT), bilirrubina direta (BD) e indireta (BI), úréia, creatinina, leucócitos e plaquetas); exames laboratoriais específicos (sorologia, data da primeira, da segunda e da terceira amostra, resultado da primeira, segundo e terceira amostra e isolamento viral) e conclusão com data dos primeiros sintomas, data da notificação, internação, óbito e classificação final.
Classificação clínica. As formas clínicas foram classificadas em três categorias: leve, moderada e grave. Leve: febre discreta e cefaléia, às vezes tontura e mal-estar de evolução fugaz; moderada: febre alta e cefaléia de início abrupto, icterícia leve, outras manifestações inespecíficas e sinal de Faget; e grave: os que não evoluíram para remissão com cura, apresentando exacerbação dos sintomas das formas anteriores, manifestações hemorrágicas, sintomas de insuficiência hepato-renal, prostração intensa e evolução para coma.

Considerações éticas. 0 estudo foi submetido ao comitê de ética em pesquisa da Universidade Federal de Minas Gerais, aprovado pelo parecer $n^{0}$ ETIC 220/07 e desenvolvido de modo a garantir o cumprimento dos preceitos da resolução 196/96 da Comissão Nacional de Ética em Pesquisa.

\section{RESULTADOS}

Inicialmente, foi levantada hipótese diagnóstica de intoxicação exógena. Ainda buscando alguma fonte comum, já que a doença se distribuía em uma única localidade rural, suspeitou-se de hepatite. Devido à epidemiologia regional, suspeitou-se de rickettsiose. E também de dengue, que naquele mesmo período, acometia a região do Médio e Baixo Vale do Jequitinhonha.

À medida que a investigação avançou, fortificou a suspeita de uma doença freqüente na região, a leptospirose, tal suspeita foi reforçada pela análise de hemogramas que apresentavam leucocitose e neutrofilia com desvio à esquerda. Neste momento, dois doentes foram ao óbito.

Diante desta situação, o serviço local de saúde notificou os casos e encaminhou amostra sorológica para investigação de suspeita destas doenças. Enquanto aguardavam o resultado sorológico, os doentes foram mantidos sob controle de sinais clínicos em unidade hospitalar e submetidos a medidas de desintoxicação e de antibioticoterapia contra Leptospira. Como ação preventiva, a equipe de vigilância à saúde iniciou investigação local e orientação da população. As sorologias realizadas apresentaram resultados negativos para as referidas doenças.

É importante ressaltar que, até aquele momento, a região era considerada indene para FA e a cobertura vacinal contra FA no município índice, no ano de 2002, atingia 138,9\%, o que dificultou suspeitar de FA. Entretanto, como medida de rotina recomendada pelo Ministério da Saúde, o laboratório procedeu à investigação de síndromes hemorrágicas nas amostras de soro. 0 resultado sorológico foi positivo para FA.

Concluindo tratar-se de casos de FA, as equipes de saúde dos três órgãos federados, mobilizaram forças no sentido de controlar a situação. Desenvolveram ações de vacinação em massa e de casa-a-casa, busca ativa de suspeitos e orientação à população.

Foram levantados dados dos locais frequientados pelos primeiros casos nos dias anteriores ao aparecimento dos primeiros sintomas. A investigação identificou que os dois primeiros indivíduos a adoecer não se deslocaram da região nos 10 dias que antecederam o início dos sintomas. A distribuição da doença demonstra ainda que o intervalo entre os casos não 
ultrapassou o período de incubação da moléstia, concentrando seu maior número de casos, na primeira quinzena de janeiro de 2003 (Figura 3). A investigação para epizootia foi positiva.

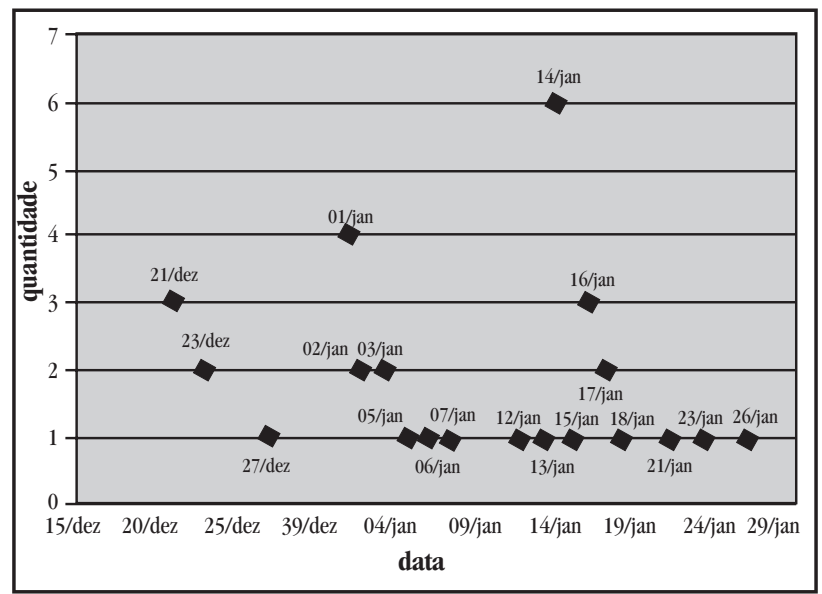

FIGURA 3

Febre amarela: distribuição por data dos primeiros sintomas. Gerência Regional de Saúde: Diamantina/MG, Brasil, 2002/2003.

Entre os 36 casos, $33(91,7 \%)$ eram do sexo masculino. A idade variou entre 16 a 67 anos; 11 (30,6\%) com idade até 29 anos, 22 (61,1\%) entre 30 e 59 anos e 3 (8,3\%) com idade superior a 60 anos. Pertenciam ao município de Serro, 18 (50\%) casos, $14(38,9 \%)$ ao município de Sabinopólis e 4 (11,1\%) ao município de Alvorada de Minas, sendo todos os indivíduos residentes na região rural. Confirmou-se por critério clínico laboratorial o diagnóstico em 33 (91,7\%) casos; em 3 (8,3\%) o diagnóstico foi feito por critério clínico-epidemiológico, estando estes últimos entre os 4 primeiros casos notificados, todos procedentes da localidade de Ribeirão do Lucas, distrito do Serro (Tabela 1).

A incidência de febre amarela acompanhou as margens dos afluentes da bacia hidrográfica do Rio Doce, rota turística da Estrada Real. Os doentes procediam dos arredores do Rio Guanhães e dos córregos Almeida, Barbosa, Bom Sucesso, São Francisco, dos ribeirões do Lucas, Santana e Brumado, das cachoeiras da Lagoa e dos Simões e outras comunidades circunvizinhas, sendo 13 (36,1\%) do Ribeirão do Lucas.

Ainda na avaliação geográfica, identificou-se que a região havia sofrido desmatamentos recentes e que os municípios envolvidos delimitam-se entre si nas divisas de águas citadas acima, tendo o Rio Guanhães como principal divisor entre elas. Segundo os relatórios entomológicos do PCFAD, não existiam mosquitos Aedes aegypti nas áreas urbanas destes municípios no ano de 2002.

Em relação ao estado vacinal dos que adoeceram, 25 (69,4\%) não eram vacinados previamente e em 11 (30,6\%) doentes, todos do sexo masculino, com estado vacinal ignorado (Tabela 1). A cobertura vacinal contra FA nos municípios de Alvorada de Minas, Sabinopólis e Serro atingiam respectivamente, 93,3\%, 90,1\% e $138,9 \%$ na soma das doses de vacinas aplicadas no período de 2000 a 2002.

As principais manifestações clínicas observadas foram: febre 34 (94,4\%), cefaléia 29 (80,6\%), vômito 25 (69,4\%), icterícia

\section{TABELA 1}

Febre amarela: distribuição por sexo, faixa etária, município, critério de confirmação, situação vacinal, hospitalização e óbito. Gerência Regional de Saúde de Diamantina/ MG, Brasil, 2002-2003.

\begin{tabular}{|c|c|c|c|c|c|c|}
\hline & \multicolumn{2}{|c|}{ Masculino } & \multicolumn{2}{|c|}{ Feminino } & \multicolumn{2}{|c|}{ Total } \\
\hline & $\mathrm{n}^{\mathrm{o}}$ & $\%$ & $\mathrm{n}^{\underline{0}}$ & $\%$ & $\mathrm{n}^{0}$ & $\%$ \\
\hline \multicolumn{7}{|l|}{ Faixa etária (anos) } \\
\hline 15 a 29 & 9 & 81,8 & 2 & 18,2 & 11 & 30,6 \\
\hline 30 a 59 & 21 & 95,5 & 1 & 04,6 & 22 & 61,1 \\
\hline$\geq 60$ & 3 & 100,0 & 0 & - & 3 & 8,3 \\
\hline \multicolumn{7}{|l|}{ Município } \\
\hline Serro & 17 & 51,5 & 1 & 33,3 & 18 & 50,0 \\
\hline Sabinópolis & 13 & 39,4 & 1 & 33,3 & 14 & 38,9 \\
\hline Alvorada de Minas & 3 & 9,1 & 1 & 33,3 & 4 & 11,1 \\
\hline \multicolumn{7}{|l|}{ Critério de confirmação } \\
\hline laboratorial & 30 & 90,9 & 3 & 100,0 & 33 & 91,7 \\
\hline clínico epidemiológico & 3 & 9,1 & 0 & - & 3 & 8,3 \\
\hline \multicolumn{7}{|l|}{ Situação vacinal } \\
\hline ignorado & 11 & 30,6 & 0 & - & 11 & 30,6 \\
\hline não vacinado & 22 & 57,40 & 3 & 12 & 25 & 69,4 \\
\hline vacinado & 0 & - & 0 & - & 0 & - \\
\hline \multicolumn{7}{|l|}{ Hospitalização } \\
\hline internado & 23 & 67,7 & 2 & 100,0 & 25 & 69,4 \\
\hline não internado & 10 & 32,4 & 1 & - & 11 & 30,6 \\
\hline Óbito & 12 & 100,0 & 0 & - & 12 & 100,0 \\
\hline Total & 33 & 91,7 & 3 & 08,3 & 36 & 100,0 \\
\hline
\end{tabular}

Nota: Os casos confirmados por critério clínico epidemiológico pertencem ao Ribeirão do Lucas/Serro e ao grupo dos quatro primeiros casos notificados.

$22(61,1 \%)$, mialgia $10(27,8 \%)$ e oligúria $6(16,7 \%)$ e os sinais hemorrágicos apresentados foram: melena $12(33,3 \%)$, hematêmese 8 (22,2\%) e hematúria 7 (19,4\%) (Tabela 2).

Não ocorreram óbitos nos doentes em idade de 60 anos ou mais; entre 30 a 59 anos a letalidade atingiu 45,5\% (10 doentes) e dos 15 aos 29 anos houve 2 (18\%) óbitos. Ao todo foram 12 óbitos; a letalidade geral chegou a 33,3\% e todos os óbitos ocorreram em pacientes do sexo masculino.

As taxas de incidência e de mortalidade calculadas com base na população rural atingiram respectivamente 1,68/1.000 e 0,42/1.000 no município de Alvorada de Minas, 2,13/1.000

TABELA 2

Febre amarela: distribuição das manifestações clínicas. Gerência Regional de Saúde de Diamantina/MG, Brasil, 2002-2003.

\begin{tabular}{|c|c|c|c|c|c|c|}
\hline \multirow{2}{*}{$\begin{array}{l}\text { Manifestações } \\
\text { clínicas }\end{array}$} & \multicolumn{2}{|c|}{ Presente } & \multicolumn{2}{|c|}{ Ausente } & \multicolumn{2}{|c|}{ Ignorado } \\
\hline & $\mathrm{n}^{0}$ & $\%$ & $\mathrm{n}^{\mathrm{O}}$ & $\%$ & $\mathrm{n}^{0}$ & $\%$ \\
\hline Febre & 34 & 94,4 & 1 & 2,8 & 1 & 2,8 \\
\hline Icterícia & 22 & 61,1 & 7 & 19,4 & 7 & 19,4 \\
\hline Vômito & 25 & 69,4 & 6 & 16,7 & 5 & 13,9 \\
\hline Cefaléia & 29 & 80,6 & 2 & 5,6 & 5 & 13,9 \\
\hline Oligúria & 6 & 16,7 & 13 & 36,1 & 17 & 47,2 \\
\hline Melena & 12 & 33,3 & 16 & 44,4 & 8 & 22,2 \\
\hline Hematêmese & 8 & 22,2 & 15 & 41,7 & 13 & 36,1 \\
\hline Hematúria & 7 & 19,4 & 12 & 33,3 & 17 & 47,2 \\
\hline Mialgia & 10 & 27,8 & 5 & 13,9 & 21 & 58,3 \\
\hline
\end{tabular}


e 0,61/1.000 em Sabinópolis e 1,95/1.000 e 0,76/1.000 no Serro.

0 período entre o início dos sintomas; até a data do óbito; variou de 3 a 15 dias com mediana de 7,5 dias e entre a data da internação e a data do óbito o período variou de 2 a 8 dias com mediana de 8 dias. A mediana do período entre a data do início dos sintomas e a notificação atingiu 4 dias com variação de -1 a 25 dias. 0 período entre a data do início dos sintomas e a data de coleta da primeira amostra variou de -1 a 27 dias, mediana de 5 dias; entre data de internação, variou de -4 a 10 dias com mediana de 3 dias. Três casos iniciaram os sintomas após a internação e dois casos resultantes de busca ativa, foram notificadas e colhidas amostras antes do inicio de sintomas, o que justifica os resultados negativos (Tabela 3).

A mediana do intervalo de tempo entre a data de início de sintomas e a data de coleta da amostra do Mac-ELISA com resultado positivo foi de 8 dias. As amostras colhidas entre 1 a 5 dias após início dos sintomas tiveram $50 \%$ de positividade; de 6 a 10 dias $85,7 \%$ de positividade e após 11 ou mais dias todas foram positivas (Tabela 4 ).

Três $(8,3 \%)$ casos foram classificados como leves, 14 (38,9\%) como moderados e 19 (52,8\%) como graves; todos os casos graves eram do sexo masculino. Com relação à idade, observou-se que mais da metade (18) dos casos de 15 a 59 anos eram graves (Tabela 5).

Os resultados dos exames bioquímicos de sangue foram bastante heterogêneos. A concentração média de bilirrubinas apresentou aumento progressivo de acordo com a gravidade clínica. Com relação aos marcadores de função renal, a uréia variou de $10-175 \mathrm{mg} / \mathrm{dl}$. E a concentração da creatinina variou de $0.6-13 \mathrm{mg} / \mathrm{dl}$ (Tabela 6).

\section{TABELA 3}

Febre amarela: intervalo em dias entre a data de início de sintomas, internação, notificação, coleta da primeira amostra e óbito. Gerência Regional de Saúde de Diamantina/ MG, Brasil, 2002/2003.

\begin{tabular}{|c|c|c|c|c|c|c|c|c|}
\hline Intervalo (dias) & Número & Mediana & Média & Mínimo & Máximo & $\begin{array}{c}\text { Intervalo de confiança } \\
\qquad 95 \%\end{array}$ & $\begin{array}{l}\text { Desvio } \\
\text { padrão }\end{array}$ & $\begin{array}{l}\text { Coeficiente } \\
\text { de variação }\end{array}$ \\
\hline Entre a data de início de sintomas e a data de internação & 23 & 3 & 3,38 & -4 & 10 & -4 a 9,43 & 3,8 & 112,42 \\
\hline Entre a data de início de sintomas e a data da notificação & 34 & 4 & 4,46 & -1 & 25 & -1 a 23,3 & 5,58 & 102,20 \\
\hline Entre a data de início de sintomase a data de coleta da primeira amostra & 31 & 5 & 6,5 & -1 & 27 & -1 a 23,13 & 5,97 & 91,85 \\
\hline Entre a data de início de sintomase a data do óbito & 10 & 7,5 & 7,18 & 3 & 15 & 3 a 13,5 & 2,81 & 39,13 \\
\hline Entre a data de internaçãoe a data do óbito & 8 & 8 & 4,56 & 2 & 8 & 2,2 a 7,6 & 0,83 & 18,20 \\
\hline
\end{tabular}

Nota: Justificativa para os casos negativos: três casos apresentaram início de sintomas após a data de internação. Dois casos resultantes de busca ativa foram notificados e colhidos amostra antes do início de sintomas.

TABELA 4

Febre amarela: resultado das amostras sanguíneas submetidas ao Mac-ELISA e intervalo entre a data de início de sintomas e o período de coleta da amostra. Gerência Regional de Saúde de Diamantina/MG, Brasil, 2002/2003.

\begin{tabular}{|c|c|c|c|c|c|c|c|c|}
\hline \multirow[t]{2}{*}{ Período de coleta } & \multicolumn{2}{|c|}{ Positivo } & \multicolumn{2}{|c|}{ Negativo } & \multicolumn{2}{|c|}{ Indeterminado } & \multicolumn{2}{|c|}{ Ignorado } \\
\hline & $\mathrm{n}^{\underline{0}}$ & $\%$ & $\mathrm{n}^{\mathrm{o}}$ & $\%$ & $\mathrm{n}^{0}$ & $\%$ & $\mathrm{n}^{\underline{0}}$ & $\%$ \\
\hline \multicolumn{9}{|l|}{ Assintomático } \\
\hline$<1$ & 2 & 100,0 & 0 & 0 & 0 & 0 & 0 & 0 \\
\hline \multicolumn{9}{|l|}{ Sintomas (dias) } \\
\hline 1 a 5 & 8 & 50,0 & 5 & 31,3 & 1 & 6,3 & 2 & 12,5 \\
\hline 6 a 10 & 12 & 85,7 & 1 & 7,1 & 1 & 7,1 & 0 & 0 \\
\hline 11 a 15 & 6 & 100,0 & 0 & 0 & 0 & 0 & 0 & 0 \\
\hline$>15$ & 3 & 100,0 & 0 & 0 & 0 & 0 & 0 & 0 \\
\hline Total & 31 & 72,1 & 6 & 13,9 & 2 & 4,7 & 4 & 9,3 \\
\hline
\end{tabular}


TABELA 5

Febre amarela: classificação clínica por sexo, faixa etária, município, hospitalização, óbito. GRS-Diamantina/MG, Brasil, 2002/2003.

\begin{tabular}{|c|c|c|c|c|c|c|}
\hline & \multicolumn{2}{|c|}{ Leve } & \multicolumn{2}{|c|}{ Moderada } & \multicolumn{2}{|c|}{ Grave } \\
\hline & $\mathrm{n}^{\underline{0}}$ & $\%$ & $\mathrm{n}^{\mathrm{0}}$ & $\%$ & $\mathrm{n}^{\underline{0}}$ & $\%$ \\
\hline \multicolumn{7}{|l|}{ Sexo } \\
\hline masculino & 2 & 66,7 & 12 & 85,7 & 19 & 100,0 \\
\hline feminino & 1 & 33,3 & 2 & 14,3 & 0 & - \\
\hline \multicolumn{7}{|l|}{ Faixa etária (anos) } \\
\hline $15-29$ & 1 & 33,3 & 4 & 28,6 & 6 & 31,6 \\
\hline $30-59$ & 1 & 33,3 & 9 & 64,3 & 12 & 63,2 \\
\hline$\geq 60$ & 1 & 33,3 & 1 & 07,1 & 1 & 5,2 \\
\hline \multicolumn{7}{|l|}{ Município } \\
\hline Alvorada & 0 & - & 2 & 14,3 & 2 & 10,5 \\
\hline Sabinopólis & 3 & 100,0 & 3 & 21,4 & 8 & 42,1 \\
\hline Serro & 0 & - & 9 & 64,3 & 9 & 47,4 \\
\hline Hospitalização & 1 & 33,3 & 11 & 78,6 & 13 & 68,4 \\
\hline Óbito & 0 & - & 2 & 16,7 & 10 & 83,3 \\
\hline Hospitalização/óbito* & 0 & - & 2 & 25,0 & 7 & 75,0 \\
\hline Total & 3 & 8,3 & 14 & 38,9 & 19 & 52,8 \\
\hline
\end{tabular}

*Proporção de doentes hospitalizados entre os doentes que foram ao óbito.

\section{DISCUSSÃo}

Neste surto, os resultados apontam para a vigilância laboratorial das síndromes febris ictéricas e/ou hemorrágicas como fator determinante no diagnóstico da moléstia. Na vigência de outros casos já diagnosticados, a suspeita de FA não é difícil, entretanto, em áreas consideradas indenes, o diagnóstico diferencial das formas leves e moderadas é difícil. A história clínica, os antecedentes epidemiológicos e a realização precoce de exames laboratoriais são fundamentais para o esclarecimento do diagnóstico que pode ser confundido com outras febres hemorrágicas, malária, hepatite, septicemia, rickettsiose, intoxicações e leptospirose, esta última pode apresentar leucocitose com neutrofilia e intenso desvio á esquerda, semelhante à FA na fase inicial ${ }^{1719}$

O teste de ELISA-IgM é muito útil no diagnóstico rápido das infecções correntes e/ou recentes, pois usualmente esta imunoglobolina surge na primeira semana após o início dos sintomas, alcança um pico na segunda semana e perdura por 2 a 3 meses $^{12}$. No caso presente, a positividade observada foi de $72,1 \%$. Cumpre assinalar que $16(37,2 \%)$ das amostras foram coletadas em indivíduos com 1 a 5 dias de início de sintomas. A presença de anticorpos IgM nas arboviroses tem sido detectada por este teste nos primeiros 8 dias após o início dos sintomas, mais comumente a partir do quarto dia, o que explicaria o resultado negativo em algumas amostras ${ }^{14}$.

A análise geográfica identificou que os casos de FA acompanharam as margens dos afluentes da bacia hidrográfica do Rio Doce, na rota turística da Estrada Real e deduz uma hipótese de relação entre os desmatamentos e o surto da doença, uma vez que revelou, múltiplos pontos de desmatamento na região. Estes achados corroboram com os resultados de Brito-Mello e cols,

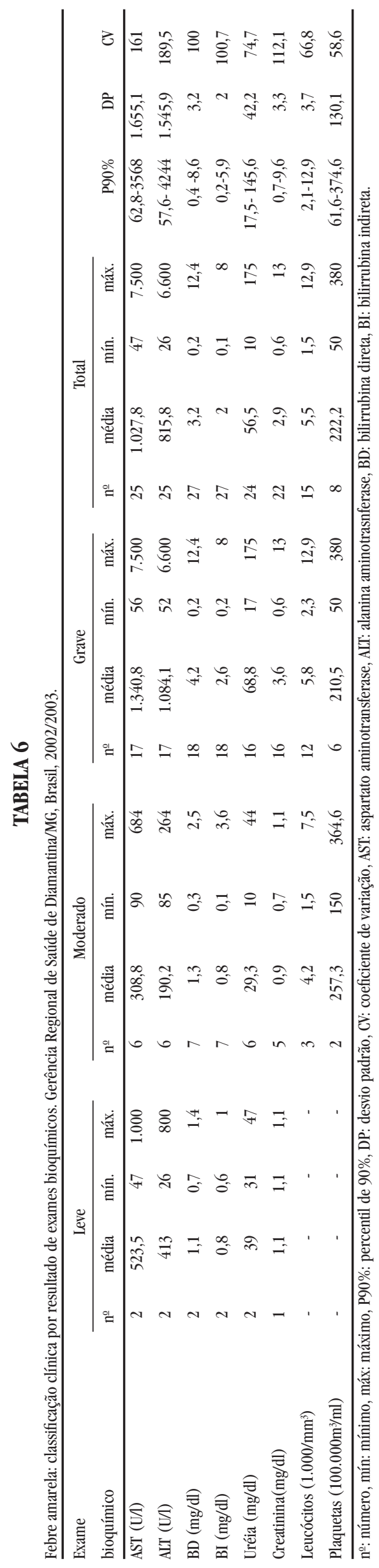


ao analisar os fatores associados com o episódio de surto de FA nessa mesma regiã $0^{2}$.

A permanência de doentes no ambiente florestal onde está ocorrendo derrubada de mata, esclarece o provável local da infecção e evidencia a ocorrência da moléstia. A intensa comunicação rodoviária e/ou ferroviária entre áreas indenes e áreas de circulação do vírus da FA faz supor alto risco para a doença em viajantes que mantenham contato com estes ambientes $^{6}$. 0 turismo ecológico foi identificado como prática de risco para a infecção nos casos de FA de 1985 em São Paulo, de 2000 nos Estados de Goiás, Bahia, Distrito Federal, Minas Gerais e São Paulo, de 2001 em MG e de 2008 em Goiás e Mato Grosso do $\mathrm{Sul}^{236715}$.

Recentemente, a região deste estudo tem recebido estímulos para desenvolver seu potencial econômico. Órgãos governamentais, por meio do Programa de Desenvolvimento do Turismo (PRODETUR) desenvolvem estratégias de atração de turistas e da indústria turística, divulgando a capacidade regional para o ecoturismo e o turismo cultural, fortalecendo as capacidades receptivas locais e, inclusive, pavimentando estradas de rodagem. Além disso, uma mineradora tem construído acessos para a retirada e transporte de mineral.

Como consequiência deste desenvolvimento, são esperadas modificações ambientais incluindo derrubada de árvores, destruição de outros tipos de vegetação, intensificação do volume de tráfego e da movimentação humana. Mesmo sob o arrefecimento dos interesses econômicos e turísticos da região, a população local e os visitantes devem ser informados a respeito do ciclo silvestre da FA, da probabilidade de se infectarem e dos meios disponíveis de profilaxia. Isto poderia reduzir o risco de infecção e o deslocamento de vírus para centros urbanos.

Os homens são afetados com uma frequiência quatro vezes maior do que as mulheres. A maior proporção de infecção observada no sexo masculino pode ser explicada pela maior resistência para se vacinar, menor acesso à vacina e maior exposição (atividades ocupacionais ou de lazer); as mulheres por terem o hábito de levar as crianças às salas de vacinação, têm maior acesso à informação e à vacina ${ }^{8}$. Este estudo mostra predominância de doentes do sexo masculino, numa frequiência dez vezes maior quando comparada ao sexo feminino; todos os casos graves e todos os óbitos por FA ocorreram entre os homens. A alta proporção de homens que não souberam informar sua situação vacinal reforça a hipótese de que os homens têm maior resistência, menor acesso e pouca informação em relação à vacinação de FA.

Nesse trabalho, não foi identificado caso confirmado da doença em crianças. Autores concordam que são acometidas em menor frequiência do que nos adultos, indicando (1) uma boa cobertura vacinal neste grupo etário e (2) que as pessoas não estão sendo infectadas no domicílio ou no peridomicílio ${ }^{25} 1422$.

No município índice, a campanha de vacinação do ano de 2002 ocorreu no momento de uma festa folclórica sendo vacinada não apenas a população residente, mas também os visitantes. Portanto, apesar do município ter atingido uma alta cobertura de doses aplicadas, estas não foram ministradas, em sua totalidade, na população residente; a população rural, que devido à distância e condições de tráfego das estradas, tem seu acesso aos serviços de saúde dificultada, recebeu menor cobertura vacinal. Uma vez que o SI-PNI registra doses aplicadas e não indivíduos vacinados, não é possível identificar quem são e onde estão as pessoas que receberam a vacina. 0 serviço da vigilância fica desprovido de instrumentos hábeis para identificar bolsões em risco de ocorrência de surtos de FA. Tais fatos indicam a necessidade de inclusão, informatizada da identificação e do endereço das pessoas vacinadas contra FA no registro municipal e também no SI-PNI, permitindo a identificação e facilitando a monitorização de populações sob risco.

0 surto teve duração de dezembro de 2002 a janeiro de 2003. Relatos prévios mostram que a doença tem caráter sazonal, ocorrendo com maior freqüência entre os meses de janeiro a abril. No Brasil, a análise de série histórica revela oscilações periódicas e regulares, prevalecendo a infecção entre os meses de novembro a junho. Intervenções pontuais como intensificação da vacinação, influenciam a tendência geral da ocorrência da FA de forma decrescente ${ }^{8}$.

A primeira fase da doença representa $90 \%$ dos casos de infecção e é caracterizada pelas formas leves e moderadas ${ }^{17} 1819$. Segundo a pirâmide de manifestações clínicas para FA da OMS, somente 20 a 30\% do número total de casos vão apresentar febre $^{17}$. Com a porcentagem de mais de $90 \%$ de relato de febre nos indivíduos da amostra, podemos inferir que cerca de $60 \%$ dos casos não foram identificados, desenvolvendo a infecção de forma assintomática ou oligossintomática.

O Ministério da Saúde ${ }^{9}$, ao analisar as manifestações clínicas da população total do surto de 2002/2003 em MG, identificou febre em $79,4 \%$, cefaléia em $79,4 \%$, vômitos em $76,2 \%$, icterícia em $63,5 \%$, calafrio em 50,8\%, oligúria em 15,9\%, melena em 28,6\%, hematêmese em 19\% e bradicardia em 19\% dos registros, o que reforça a proposição acima. Entretanto, essa não foi uma singularidade neste surto, pois Tuboi $e$ cols ao analisar casos registrados de FA no Brasil, do período de 1998-2002, encontrou registro de sintomas de febre em 94,4\%, cefaléia em $83,3 \%$, vômito em $75,8 \%$, icterícia em $69,1 \%$, calafrio em $63,5 \%$, manifestações hemorrágicas em $46,4 \%$, oliguria ou anúria em $36,7 \%$, coma em $26,6 \%$, choque em 19,3\% e bradicardia em 9,8\% dos casos do SINAN, corroborando que a vigilância do país têm identificado somente cerca de $40 \%$ dos $\operatorname{casos}^{21}$.

A análise laboratorial identificou em todos os exames elevação de AST, e a ALT com 91,2\% dos resultados acima dos valores normais, sendo que, $92 \%$ das transaminases tiveram valores superiores a duas vezes os valores normais. As alterações acima dos valores normais nas bilirrubinas tiveram predomínio da fração direta. A creatinina apresentou elevação discreta; a uréia não chegou a quatro vezes os valores normais. A literatura pesquisada confirma que, bioquimicamente, as aminotransferases aumentam consideravelmente, atingindo valores acima de 1.000UI, provavelmente devido à lesão viral direta sobre 0 miocárdio, músculo esquelético e lesão hepática. Apresentam aumento também as bilirrubinas com predomínio da fração direta, o colesterol e a fosfatasse alcalina. Na fase grave da doença, os níveis de uréia e creatinina elevam-se muito, podendo alcançar 5 vezes ou mais os valores normais ${ }^{819}$. 
Os casos moderados apresentaram os menores valores médios na concentração de uréia e creatinina; estes resultados divergem dos de Tuboi $e$ cols $^{21}$ onde os casos moderados apresentaram as maiores médias de bilirrubina, uréia e creatinina, comparados aos casos leves e graves. Os valores dos exames laboratoriais dependem do momento da coleta dos exames.

A concentração média das transaminases, da uréia e da creatinina apresentaram quedas quando comparados os casos leves aos moderados e os casos graves apresentaram aumento das concentrações médias em relação aos leves e aos moderados com exceção das plaquetas. As formas leves e moderadas apresentam quadro clínico autolimitado, não há alterações laboratoriais importantes, salvo por leucopenia e discreta elevação das transaminases ${ }^{8}$.

A maior letalidade atingiu a faixa etária de 15 a 59 anos. A incidência média da doença foi de 1,92/1.000 habitantes, o que está de acordo com a literatura ${ }^{151619}$. Todos os óbitos e $60 \%$ das internações foram entre os casos graves, o que também, está de acordo com a literatura ${ }^{4}$.

A letalidade é um indicador de sensibilidade da vigilância em detectar novos casos. Considerando todas as formas da doença, espera-se uma letalidade em torno de 5 a 10\%; maiores valores sugerem uma baixa capacidade de detecção das formas leves. A letalidade média por FA no Brasil, no período de 1980 a 2003, foi de $51,1 \%{ }^{919}$. Portanto, apesar da letalidade do presente surto ter sido alta (33,3\%), permanece abaixo da média brasileira; indicando uma melhor sensibilidade da vigilância neste surto, embora ainda com falhas em detectar formas leves.

Estudo realizado por Tuboi e cols, obteve resultados semelhantes aos deste estudo, quando comparados os intervalos em dias entre a data de início de sintomas e a morte, com média de 8 dias (2-39), e entre a data da hospitalização e a morte, com média de 3 dias $(0-17)^{21}$.

Apesar das controvérsias em relação às medidas de profilaxia, todos concordam quanto à necessidade do isolamento de doentes durante o período de viremia, com a finalidade de evitar a infecção de mosquitos existentes na área, apesar de muitos virêmicos poderem ser assintomáticos ${ }^{20}$. Neste surto, os hospitais locais, devido a alta demanda para as estruturas hospitalares de pequeno porte, não tiveram condições de proporcionar isolamento. A concentração de internados sem isolamento, pode ser a explicação para os 3 casos que apresentaram início de sintomas após a internação. É importante ressaltar que os hospitais estão localizados próximos a remanescentes de florestas e de fluxos de água. Entretanto, não deve ser descartada a hipótese de infecção prévia à internação, pois, os indivíduos procediam de região rural.

Considerações finais. Recomenda-se intensificar, nesta área de circulação viral, ações de profilaxia da FA devido ao aumento do risco de expansão da forma silvestre e de urbanização da doença em consequência do desenvolvimento econômico e turístico regional.

No Brasil, as campanhas de eliminação do Aedes aegypti são intensificadas a partir de novembro; campanhas anuais de intensificação da vacinação contra FA neste mesmo período, nas áreas endêmica, de transição e de risco potencial poderiam também ser implementadas. A vacinação seria seletiva. As campanhas teriam como público alvo os adultos com foco principal nos indivíduos do sexo masculino, viajantes, regiões rurais e ecoturísticas. Poderia também ser desenvolvida atividade periódica de mobilização da população susceptível, orientando-a quanto à maior freqüência da doença nos homens, o reconhecimento de áreas com circulação viral, o grau de letalidade da doença e a disponibilização mais acessível da vacinação contra FA.

Estas medidas de saúde pública teriam como objetivo reduzir a incidência da doença nos grupos de risco e prevenir surto de $\mathrm{FA}$, como o investigado neste estudo. Os resultados do presente estudo podem contribuir para identificação precoce de surtos, propiciando a otimização do uso dos escassos recursos da saúde e a melhora da qualidade na assistência, que por sua vez, reforçam as estratégias de controle da doença e de redução da mortalidade.

Diante da expansão das áreas de risco para FA sugerem-se novos estudos que avaliem a qualidade do sistema de vigilância da FA no país no sentido de identificar quais medidas recomendadas estão sendo desenvolvidas com plenitude e eficácia.

Limitações do estudo. A avaliação de casos de FA provenientes dos municípios sob jurisdição da GRSD não reflete necessariamente o perfil verdadeiro desta doença em MG. Este mesmo surto acometeu também outros municípios vizinhos pertencentes a GRS-Itabira e o surto de 2001 atingiu outra região do estado. A subnotificação limita o real conhecimento sobre a incidência, letalidade e mortalidade da doença e também a taxa de ataque do surto.

\section{REFERÊNCIAS}

1. Araújo TP, Rodrigues SG, Costa MIWA, Vasconcelos PF, Rosa APAT. Diagnóstico sorológico de infecções por dengue e febre amarela em casos suspeitos no Estado do Pará, Brasil, 1999. Revista da Sociedade Brasileira de Medicina Tropical 35: 579-584, 2002.

2. Brito-Melo GEA, Ribeiro M, Diniz TT, Santos RAC, Araújo PH, Nunes FAR. Additional Factors Associated With the Episode of Yellow Fever in Vale Jequitinhonha Region. Vírus Reviews and Research 10:31-35, 2005.

3. Coimbra TLM, Iversson LB, Spir M, Alves VAF, Boulos M. Investigação epidemiológica de casos de febre amarela na região noroeste do estado de São Paulo, Brasil. Revista de Saúde Pública 21: 193-199, 1987.

4. Fonseca BAL, Figueiredo LTM. Febre Amarela. In: Veronesi R, Focacci R (orgs) Tratado de Infectologia, $2^{\text {a }}$ edição, São Paulo, Editora Atheneu, p. 254-259, 2002.

5. Fundação Nacional de Saúde. Vigilância Epidemiológica. Eventos Adversos Sérios Associados com a Vacina 17D contra a Febre Amarela. Ministério da Saúde, Brasília, 2002.

6. Massad E, Burattini MN, Coutinho FAB, Lopez LF. Dengue and the risk of urban fever reintroduction in São Paulo State, Brazil. Revista de Saúde Pública 37:477-484, 2003.

7. Ministério da Saúde. Boletim diário encerrado às 18 h do dia 14/03/2008. Situação da Febre Amarela Silvestre no Brasil, 2007 e 2008. Disponível em http://portal. saude.gov.br/portal/arquivos/pdf/boletim_svs_febre_amarela_14032008.pdf, acessado em 17/03/2008.

8. Ministério da Saúde. Febre Amarela. Portal da Saúde. Disponível em http://200.214.130.38/porta/saude/visualizar_texto.cfm, acessado em $05 / 10 / 2007$ 
9. Ministério da Saúde. Guia de Vigilância Epidemiológica vol I, Brasília, 214-215, 287-306, 2002.

10. Ministério da Saúde. Nota Técnica 11/01/2008. Mortes de macacos e a prevenção da febre amarela no Brasil, 2007 e 2008. Disponível em http://bvs.saude.gov.br/ bus/febreamarela/imprensa.php, acessado em 23/01/2008.

11. Ministério da Saúde. Nota Técnica n07/2006/COVEV/CGDT/DEVEP/SVS/MS. Assunto: Informar a situação epidemiológica da Febre Amarela no Brasil em 2006. Disponível em http://portal.saude.gov.br/portal/arquivos/pdf/nt_febreamarela. pdf, acessado em 23/01/2008.

12. Oliveira L, Vazelille M, Filippis AMB, Failloux AB. Aedes aegypti in Brazil: genetically differentiated populations with high susceptibility to dengue and yellow fever viruses. Royal Society of Tropical Medicine and Hygiene 1:43-54, 2004.

13. Pan-Americana Health Organization. Yellow Fever: number of cases and deaths notified to PAHO, 1985-2004. Division of Vaccines and Immunization. Pan American Health Organization, Washington, 2004.

14. Passos RA, Marques GRAM, Voltolini JC, Condino MLF. Dominância de Aedes aegypti sobre Aedes albopictus no litoral sudeste do Brasil. Revista Saúde Pública 37:729-734, 2003.

15. Robert ES. Introdução ao vírus de febres hemorrágicas. In: Bennett JC, Plum F (eds) Cecil Tratado de Medicina Interna. 20 edição, Volume 2; Guanabara Koogan, Rio de Janeiro, 1984-1986, 1997.

16. Rouquayrol NAF. Epidemiologia \& Saúde. Editora Medsi, Rio de Janeiro, p.280-281, 2003

17. Secretaria de Vigilância em Saúde. Departamento de Vigilância Epidemiológica. Doenças infecciosas e parasitárias: guia de bolso. $4^{\mathrm{a}}$ edição ampliada. Brasília, p.133-136, 2004
18. Secretaria de Vigilância em Saúde. Departamento de Vigilância Epidemiológica. Manual de Vigilância Epidemiológica de Febre Amarela. Brasília, 2004.

19. Secretaria de Vigilância em Saúde. Secretária de Vigilância em Saúde. Guia de Vigilância Epidemiológica. 6a edição. Brasília, p.307-325, 2005.

20. Tauil PL. Controvérsias atuais sobre a vacinação de febre amarela no Brasil. Boletim Eletrônico da Sociedade Brasileira de Medicina Tropical n ${ }^{0} 5,23$ de setembro de 2005.

21. Tuboi SH, Costa ZGA, Vasconcelos PFC, Hatch D. Clinical and epidemiological characteristics of yellow fever in Brazil: analysis of reported cases 1998-2002. The Royal Society of Tropical Medicine and Hygiene 101:169-175,2007.

22. Vasconcelos PFC, Rodrigues SG, Degallier N, Moraes MAP, Rosa JFST, Rosa EST, Mondet B, Barros VLRS, Rosa APAT. An Epidemic of sylvatic yellow fever in the southeast region of Maranhão State, Brazil, 1993-1994: Epidemiologic and entomologic findings. The American Journal Tropical Medicine Hygiene 57:132$137,1997$.

23. World Health Organization. Yellow fever - Technical Consensus Meeting. Emerging and other Communicable Disease, Surveillance and Control. Geneva, 1998.

24. World Health Organization. Yellow fever. Epidemic and Pandemic Alert and Response: diseases coverd by EPR. Disponível em http://www.who.int/csr/disease/ yellowfev/trends/en/, acessado em 03/10/2007.

25. World Health Organization. Yellow fever. Fact Sheet $n^{0} 100$, revised december 2001. Disponível em http://www.who.int/mediacentre/factsheets/fs100/en/, acessado em 03/10/2007. 